\title{
Complementing South African inflation surveys: A suitable forecasting tool
}

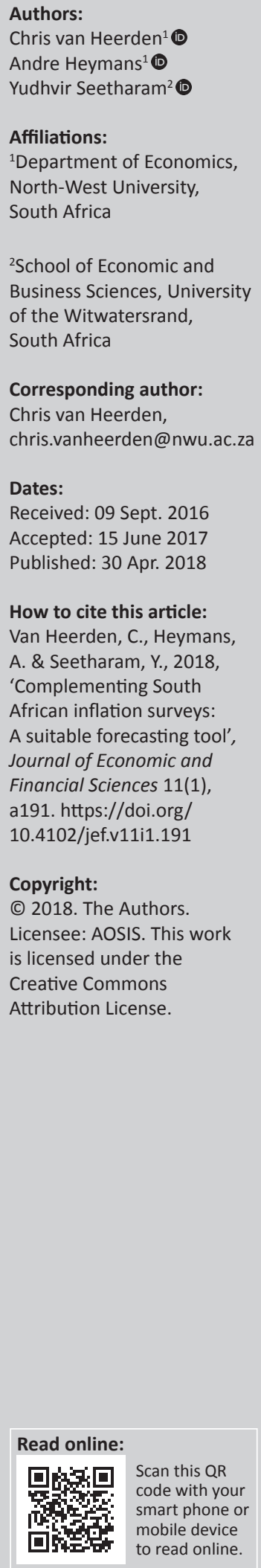

Central banks currently perform inflation expectation surveys in order to better align their inflation expectations with that of the general public. However, surveys are time-consuming, complicated, expensive and not always accurate, thus compromising the credibility of these expectations. The complexity of inflation targeting and the difficulty of forecasting in real time can also cause policymakers to consider more basic models, which can lead to inexact forecasts. This article employs less complicated models, such as the seasonally adjusted autoregressive integrated moving average and Holt-Winters exponential smoothing models, to provide equally reliable forecasts. A more complex approach in the form of a non-linear autoregressive neural network process was also employed to model the strategic and rational manner in which the general public formulates their expectations. Overall, the forecast estimates provided by these models were superior when compared with the inflation expectations provided by the International Monetary Fund, South African Reserve Bank and Bureau for Economic Research.

\section{Introduction}

Inflation targeting, as a preferred framework for monetary policy, has been adopted by several central banks since the 1990s (Naraidoo \& Gupta 2010). South Africa adopted this approach in February 2000, when an inflation target range of 3\%-6\% was announced for first achievement in 2002 (Van der Merwe 2004). Naraidoo and Gupta (2010) argued that the reason for an inflation targeting framework is because it is seen as the nominal anchor for monetary policy. They also argued that the main reason for banks choosing to switch to an inflation targeting framework was failures in their previous monetary policy frameworks, based on intermediate exchange rate targets and their choice of monetary aggregates (De la Dehesa 2008). Inflation targeting can also have a positive effect on a country, where it can improve the required discipline in the setting of an essential monetary policy (Demir \& Yigit 2008), which can escalate macroeconomic stability (Clarida, Gali \& Gertler 2000). Maintaining price stability may also guide an economy to employment creation and to sustainable growth (Epstein \& Yeldan 2008). Future investment and monetary policy decisions and future private sector consumption decisions are also contingent on inflation rate expectations (Mehrotra \& Sánchez-Fung 2008).

This implies that monetary policy, as a forward looking approach, requires control over long-run expectations, as it can have a significant influence on investment and savings decisions, wage formation and the determination of nominal interest rates (Setterfield 2006). The study of Friedman (1968) emphasised the importance of long-run expectations from a monetary policy perspective, especially because of the time lag between the implementation of monetary policies and the effect of the policy on the economy. The importance of an effective communication channel with the general public is also highlighted by Rossouw (2005), who argues that if the general public does not accept the rate of inflation as a true reflection of price increases, inflation targeting could be forfeited in the long run. It is, therefore, important to maintain credibility by providing accurate inflation rate forecasting values (Woglom 2005), as it can lead to accurate inflation announcements, and controlling the frequency of these announcements can lead to a positive influence on public expectations (Demir \& Yigit 2008). Inflation-forecast targeting can thus be seen as the optimal intermediate targeting rule (Svensson 1999:627).

This leads to the goal of this article, to establish a forecasting tool that can be used instead of timeconsuming surveys, to promote more effective alignment between the expectations of the broader public (consumers, producers, investors, unions, policymakers, analysts and other market participants) in South Africa. In order to improve on the current survey methodology, the model proposed to improve the correlation between the South African Reserve Bank (SARB) and the 
general public must have the ability to replicate the strategic nature of a decision maker's thought process. To this end, we propose the use of artificial neural networks (ANNs) to generate inflation expectations. McCulloch and Pitts (1943) first introduced ANNs for the modelling of the biological neural network of a human brain, which makes this approach most ideal to mimic the method of formulating expectations and month-to-month decisions by the general public.

The notion for considering ANN modelling is not implausible, as it has already proven to be useful in some economic, financial, business and engineering applications (see, e.g., Fernández-Rodríguez, González-Martel \& Sosvilla-Rivero 2000; Rafiq, Bugmann \& Easterbrook 2001; Vellido, Lisboa \& Vaughan 1999). Artificial neural network modelling was also used by some central banks, including the Bank of Canada (Tkacz \& Hu 1999), the Bank of Jamaica (Serju 2002) and the Czech National Bank (Hlaváček, Koňák \& Čada 2005). This is because ANN modelling is renowned for its greater flexibility and dominance over the forecasting ability of linear models (see, e.g., Swanson \& White 1997). Furthermore, as real-world systems are often found to be non-linear (Granger \& Terasvirta 1993), other non-linear forecasting models, such as the threshold autoregressive model (Tong \& Lim 1980) and the autoregressive conditional heteroscedastic model (Engle 1982), may flounder, as ANN modelling is better equipped compared to prespecified linear and non-linear models to capture the vast number of possible non-linear patterns without prior knowledge of the relationships present (Zhang, Patuwo \& Hu 1998). To account for temporal relationships between the input variable(s) and output variable, the use of a subset of ANNs, that of recurrent neural networks (RNNs) is suggested (Elman 1991).

There is, however, some dispute over the efficacy of ANN models over shorter time frames, while autoregressive integrated moving average (ARIMA) models are said to provide reliable short-term forecasts (Maier \& Dandy 1996). Settling on one or the other (ANN or ARIMA models) is seemingly some time off. Faraway and Chatfield (1998) and $\mathrm{Au}$, Choi and $\mathrm{Yu}$ (2008), for example, reported on the superiority of ANN models over other forecasting models, such as the Box-Jenkins approach (Box \& Jenkins 1976), the Holt-Winters exponential smoothing model (Winters 1960) and the seasonally adjusted autoregressive integrated moving average (SARIMA) model. Other studies, such as those performed by Franses and Draisma (1997) and Alon, Qi and Sadowksi (2001), further stressed this by stating that ANN models are capable of modelling both seasonal and trend effects, without the need to remove it from the data.

Contradictory evidence suggests, however, that the performance of ANN models is not considerably different from that of the ARIMA model (Caire, Hatabian \& Muller 1992) or the automatic Box-Jenkins approach (Sharda \& Patil 1990). Autoregressive integrated moving average-type models are popular for their established ability to deal with stationary and non-stationary series with seasonal and nonseasonal elements (Pankratz 1983) and their dominance over other forecasting models such as the Holt-Winters exponential smoothing model and the Grey forecasting model (Deng 1982) (see, e.g., Chen, Chang \& Chang 2009). However, there are also some studies that found some ARIMA-type models being outperformed by the Holt-Winters model (see, e.g., Da Veiga et al. 2014).

To address the conflicting arguments above, this article will compare the forecasting ability of the non-linear autoregressive (NAR) networks with that of less complex models, such as the additive Holt-Winters exponential smoothing model and the SARIMA model, to account for the presence of inflation seasonality (Kinda 2013). To contribute, therefore, to the literature of inflation forecasting, this article will focus primarily on the substitution of time-consuming surveys to enhance the alignment between the public's inflation expectations and that of policymakers in South Africa.

To verify the credibility of these forecast estimates, the root mean squared error (RMSE), the mean absolute deviation (MAD), the mean absolute percentage error (MAPE) and the Theil inequality coefficient (U) will be consulted. The inflation forecast estimates will also be compared to the expectations published by the International Monetary Fund (IMF) and SARB and to the expectation survey that is conducted by the Bureau for Economic Research (BER). To achieve these goals, this article commences by providing an overview of the underlying factors causing inflationary pressure (the 'Underlying inflationary factors in South Africa' section). This will be followed by a discussion on the credibility and transparency of the South African monetary policy ('The credibility and transparency of South African monetary policy' section) and a discussion of the data and methodology (the 'Data and methodology' section), which will be followed by an overview of ANNs, of the SARIMA model and of the Holt-Winters exponential smoothing model in the 'Artificial neural networks' section, 'The seasonally adjusted autoregressive integrated moving average model' section and 'The additive Holt-Winters exponential smoothing approach' section, respectively. The 'Results' section is followed by the 'Conclusion and recommendations' section.

\section{Underlying inflationary factors in South Africa}

The South African economy of the 1960s can be characterised by demand-pull inflation that was accompanied by a monetary expansion. By the 1970s the country was characterised by costpush inflation followed by a devaluation of the South African Rand of more than 21\% in the last week of September 1975 (Strydom \& Steenkamp 1976). Strydom and Steenkamp's 1976 study argues that institutional factors such as increases in indirect taxes, wage pressures and non-competitive market structures were also related to the inflationary process of the 1970s. The oil crisis in the 1970s and the sanctions against South Africa during the 1980s also contributed to an increase in inflation (Rangasamy 2009). Moreover, De Wet and Associates (1987) argued that intersectoral productivity differences, which 
lacked the levels of compensation (e.g. wages and salaries), market distortions (e.g. increases in indirect taxes and administered prices) and increases in import prices can be considered as one of the sources of inflation in South Africa at the time. It has been further argued that the 1980s and early 1990s were overshadowed by a weak monetary policy stance, which contributed to the high inflation rate at the time. From the early 1980s up to the end of apartheid, the growth in broad money was substantially higher compared to South Africa's trading partners, which worsened inflation even further (Ricci 2005). However, stronger monetary discipline was adopted from the early 1990s and, after the elimination of sanctions and the gradual liberalisation of controls caused real interest rates to increase, inflation was brought back under control (Ricci 2005).

More recent inflation spikes have been attributed to monetary expansion, strikes, xenophobic attacks and drought and, because of its powerful and highly centralised union movement, wage-push inflation can also be considered as a substantial issue in South Africa (Akinboade \& Niedermeier 2002). This labour union-induced cost-push inflation is further exacerbated by the weakening of the local currency (Kaseeram, Nichola \& Mainardi 2004). Woglom's (2005) study also argued that exchange rate changes are partly responsible for the knock-on effect, where changes in import prices can lead to wage changes and changes in other prices. Furthermore, even if the central bank's influence has shrunk tremendously to merely setting the policy interest rates (Epstein \& Yeldan 2008), Lim and Papi (1997) argued that policymakers' commitment to active exchange rate depreciation can further contribute to the inflationary process.

These arguments imply that the extensive swings of the South African rand (ZAR), under the free floating exchange rate regime, may have been a contributing factor to the inflationary process. The ZAR experienced significant shocks during 1970-1995 because of political events and gold price movements. Political events also led to intensified sanctions and capital outflows, leading the government to reinstate the financial rand system in September 1985 in an attempted to limit these capital outflows. By that time, some key international banks refused to renew South African credit lines, forcing the South African authorities to announce the temporary closure of the foreign-exchange market on 28 August 1985. The declaration of a complete debt standstill on South Africa's foreign debt repayments came only 4 days later on 01 September 1985, forcing the country to negotiate the rescheduling and orderly repayment of its foreign debt through a series of 'standstill arrangements'.

The financial rand was finally abandoned in 1995, relaxing the exchange control over non-South African residents and capital outflows, thus escalating the volatility of the ZAR (Van Heerden \& Heymans 2011). The ZAR also demonstrated vulnerability during the Asian crisis (1997), the Russian crisis (1998), the Brazilian crisis (1999), the Argentinean crisis (2001/2002), the global financial crisis $(2007 / 2008)$ and the Euro-debt crisis (2009). Unfortunately, the ZAR has not exhibited an extended period of recovery or stability during the post-financial crisis period, reaching a record low against the US dollar on 20 January 2016. Although this was mainly caused by the firing of the minister of finance in December 2015, poor economic prospects in China, South Africa's electricity crisis, the negative sentiment towards South Africa as an emerging market, commodity exposure and poor political decisions also played a role (Karodia \& Soni 2016).

\section{The credibility and transparency of South African monetary policy}

According to Stiglitz (2008), inflation targeting is almost destined to fail. He argues that this approach is ineffective in dealing with macroeconomic shocks, which can lead to procyclical monetary policy and ultimately amplify economic cycles. Another criticism is that the wrong measure of discretion will either lead to too much control or leave too little monetary policy flexibility (Stiglitz 2008). On the other hand, Kydland and Prescott (1977) emphasised the importance of determining the level of discretion. Emerging economies, like that of South Africa, have a tendency to be more vulnerable to exogenous shocks, which demands a greater flexibility in responding to these shocks (Kahn 2008). This implies that the first important element in increasing the flexibility of policymaking is determining the required level of discretion needed to increase monetary policy's credibility. A weak level of discretion can hinder the ability to control for the general public's inflation expectations. Without the required level of communication the general public can refuse to accept the inflation rate as the true reflection of current price increases, which can lead to the forfeiting of long-run inflation targeting (Rossouw 2005). However, too much discretion can lead to an inflationary bias in an economy, which limits the transparency and accountability of a central bank. Limiting discretion within an inflation-targeting monetary policy framework thus requires the support of the public and of the political processes (Mishkin 2004).

The South African case, however, differs from this general sceptic description, because monetary policy has promoted stability in this country, concentrating on anti-inflation bias consistency. This is achieved by placing more weight on economic output and less weight on exchange rate management (Ortiz \& Sturzenegger 2007). Furthermore, a supportive and disciplined fiscal policy has also been beneficial for the South African economy in the past (Ajam \& Aron 2009), increasing the credibility of the current inflation targeting framework. Even so, an increase in monetary policy transparency will further enable market participants to monitor the current monetary authority, thus contributing to the formulation of improved and more realistic inflation expectations that will encourage more realistic wage demands and selling price adjustments (Powers 2005). However, to ensure the continuous credibility of the SARB, a well-developed technical infrastructure is required that 
consists of quality data and insightful inflation modelling and forecasting capabilities (Kahn 2008). Quality data can be collected by means of expectation surveys, but they can become time-consuming, complicated and expensive and are not always completely accurate (Kershoff \& Smit 2002). Different conclusions have also been reached when using the same data but with different empirical methodologies (Kershoff \& Smit 2002). Moreover, Kershoff and Smit (2002) argued that panel designed surveys, by means of convenience sampling, can be biased. Nonetheless, surveys are considered to be the more dominant approach, and because surveys cannot be conducted frequently there is still a great need for alternative methods of measuring expected inflation in order to realise more desirable outcomes (Epstein \& Yeldan 2008).

\section{Data and methodology}

The monthly South African headline year-on-year consumer price index (CPI) inflation rates were sourced from Statistics SA's website (2015) for the period of January 1970 to December 2015. To verify the credibility of the forecasting models under evaluation, this article follows both a yearly and a quarterly approach. The yearly approach entails a comparison between the 2010-2015 ex post forecast estimates of the models under evaluation and the yearly expectations published by the IMF (2008-2014). The quarterly approach, on the other hand, entails a comparison between 2010 to the second quarter of 2013 ex post forecasts of the models under evaluation and the quarterly expectation survey that was conducted by the BER (2015) and the quarterly expectations published by the SARB (2016), respectively. These quarterly comparisons are based on a limited time span because of the limited availability of BER forecasts.

The eight forecast error statistics that were applied to evaluate the forecasting performance included the Akaike information criterion (AIC), the Schwarz criterion (SC), the Hannan-Quinn criterion (HQ) and the standard error (SE) of the forecasted series regressed on the original series. Furthermore, the RMSE, the MAD, the MAPE and the U were also used. These eight forecast error statistics can be illustrated as follows (Gujarati 2003; IHS 2015a):

$$
\begin{aligned}
& A I C=\frac{-2 l+2 k}{T}, \\
& S C=\frac{-2 l+(k \log T)}{T}, \\
& H Q=\frac{-2 l+2 k \log (\log (T))}{T}, \\
& S E=\sqrt{\frac{\hat{\epsilon}^{\prime} \hat{\epsilon}}{T-k},}, \\
& R M S E=\frac{\sqrt{\sum_{t=T+1}^{T+h}\left(\hat{y}_{t}-y_{t}\right)^{2}}}{h},
\end{aligned}
$$

$M A D=\frac{\sum_{t=T+1}^{T+h}\left|e_{t}\right|}{h}$,

[Eqn 6]

$M A P E=\frac{100 \times \sum_{t=T+1}^{T+h}\left|\frac{\hat{y}_{t}-y_{t}}{y_{t}}\right|}{h}$,

$U=\frac{\sqrt{\frac{1}{h} \sum_{t=T+1}^{T+h}\left(\hat{y}_{t}-y_{t}\right)^{2}}}{\sqrt{\frac{1}{h}\left(\sum_{t=T+1}^{T+h} \hat{y}_{t}^{2}\right)}+\sqrt{\frac{1}{h} \sum_{t=T+1}^{T+h} y_{t}^{2}}}$,

where $\hat{y}_{t}$ and $y_{t}$ denote the forecasted and actual value in period $t$, respectively; $l$ denotes the $\log$ likelihood; $\hat{\epsilon}^{\prime} \hat{\epsilon}$ denotes the sum of the squared residuals; $k$ denotes the number of parameters, where $h-k$ insinuates the degrees of freedom in a $k$-variable model; and $e_{t}$ is the error term at time $t$. The EViews $9{ }^{\circledR}$ econometric software program (IHS 2015b) was used to estimate the SARIMA (see the "The seasonally adjusted autoregressive integrated moving average model' section) and the Holt-Winters exponential smoothing (see 'The additive Holt-Winters exponential smoothing approach' section) forecasts, as well as the eight forecast error statistics, whereas MATLAB ${ }^{\mathrm{TM}} 8$ (The MathWorks 2010) was used to estimate the NAR forecasts (see the 'Artificial neural networks' section).

\section{Artificial neural networks}

A neural network model is effectively a mathematical model that attempts to mimic the functionality of the human brain (Bishop 1995). In its simplest form, it can be represented by a set of processes or nodes (some of which can be unknown or hidden) that would convert an input to the desired output. In contrast to traditional time series models, the neural network is seen as a black box - a model that is not required to be specified in advance, before the data are processed by it. As input variables are passed to an input node, they are processed and then passed on as output, which can either be the final output of the network or can be further passed on to another input node. Connections allow information to flow between nodes. These connections can be unidirectional or bidirectional. The various combinations of connections between nodes lead to a wide array of outputs, thus making neural networks a powerful tool in solving complex problems.

\section{Artificial neural network design}

The workings of an ANN consist of inputs that map to a particular function, which determines whether the node or neuron is activated. The mechanics of the artificial neuron (here represented by a single node) and, subsequently, the perceptron (a collection of nodes) was developed by Rosenblatt (1958) and discussed in Haykin (2009). Consider equation 9 below: 


$$
y=f(\xi)=\left\{\begin{aligned}
1, & \text { if } \sum_{i=1}^{n} w_{i} x_{i} \succeq b \\
0, & \text { if } \sum_{i=1}^{n} w_{i} x_{i} \prec b
\end{aligned}\right.
$$

A set of $i$ inputs, $\xi$, are fed into a (linear) function, $f$. If the inner (dot) product of each input with corresponding weight, $w_{i}$ is sufficient to activate the neuron, then the output, $y$, takes on a binary value of unity. The threshold value that determines activation is referred to as the bias of the neuron, $b$. Weights that are positive are said to enhance the signal and excite the neuron, whereas weights that are negative are said to inhibit the signal.

In relation to equation 9 above, there is a linear threshold gate that needs to be passed by the signal in order to activate the neuron. Thus, if the input is not considered strong enough then the neuron is not activated. If activated, the output is passed as either the final result or as an input to other neurons. This former example of network architecture is referred to as a single layer perceptron, with the latter being a multilayer perceptron. Both are examples of ANNs.

One would train the ANN by calibrating the weights based on the error between the actual and desired output. The error term is in itself a function of all the weights in the ANN and forms an irregular multidimensional complex hyperplane (an $n$-dimensional space, with planes that are not of equal size and contain complex numbers). Specialised searching techniques would be employed to find the global minima of this hyperplane, resulting in the optimal network, as the global minima corresponds to the smallest error term (and therefore a more accurate fit of the data). By this definition, it can be inferred that the global minima of the error hyperplane does not necessarily imply that the error term is eliminated in its entirety. Indeed, the global minima can be considered the acceptable standard based on the judgment of the network architect, similar to how an analyst would judge the RMSE of a regression to be acceptable. Secondly, the single layer perceptron is only suitable for linearly separable problems. For those problems that are non-linearly separable, a multilayer perceptron is used. If there are numerous thresholds to surpass, then the perceptron is referred to as multilayered. In such an architecture, further layers of nodes are placed between the input and output layers. These are referred to as hidden layers, and consequently the nodes within them are hidden. More sophisticated learning algorithms were developed to train the network in reducing the error term to an acceptable level. These algorithms, along with the type of network used, create a hierarchy of neural networks where one can select the best network architecture based on the problem at hand.

\section{The choice of artificial neural network in modelling}

Basheer and Hajmeer (2000) argued that, generally, feedforward networks where the information flows from the input to the output node only are sufficient for learning timeinvariant problems. Recurrent neural networks can be used to model time-varying problems and recognise patterns or for forecasting purposes. These networks allow for bidirectional flow of information, enabling the error term to be used as an additional input in the network. These networks can model non-linear chaotic dynamic systems and in principle should be able to predict future values of the output variable. A particular type of RNN is discussed here - that of NAR networks.

Non-linear autoregressive RNNs are a form of non-linear models, which determine current output values from past input values. A NAR network can be described as follows (Connor, Martin \& Atlas 1994):

$y(t)=f\left(u\left(t-D_{u}\right), \ldots, u(t-1), u(t)\right)$,

where $u(t)$ represents the input of the network, $D_{u}$ is the lags of the input and $f$ is a non-linear function. This model is then estimated in a software package, with careful attention to the number of hidden layers, as well as partitioning the data into training and testing sets, to ensure that the error term between the actual and predicted output remains low. Further details on the implementation of the ANN are provided in the next section.

\section{Non-linear autoregressive neural networks}

Basheer and Hajmeer (2000) provide a process for building an ANN. There are six phases to building the network. The first phase relates to defining and formulating the problem. In other words, one must hypothesise about any relationships that exist within the data, along with the appropriate family of models to test the hypothesis. The authors suggest that other techniques be explored before settling on the use of an ANN, as an ANN can be time-consuming to run, in comparison to other models. Secondly, the network must be designed, which is largely dependent on the modeller. This involves data collection, data processing and partitioning into samples for testing and evaluation. Similar to the use of testing a time series model on out-of-sample data, this approach is used in ANN modelling, to ensure that the ANN is considered robust. Thirdly, the network is trained and optimised in terms of the number of hidden nodes as well as network architecture. Fourthly, the network output is verified to determine if the error rate is acceptable when the training dataset is used. Fifthly, the network is programmed to now use non-training data; last, the system is maintained to ensure that when future datasets are provided, the error rate remains within acceptable bounds.

These steps are often provided in software packages such as MATLAB $^{\text {TM }} 8$ (The MathWorks 2010), which allow one to select the number of hidden nodes and the amount of data to be used in training and testing the ANN. To allow comparison between traditional econometric methods, the performance of neural networks can be evaluated by examining the error term. Garth et al. (1996) showed that network performance 
rests on two variables - the number of hidden layers and thus nodes in the network and the SE. The optimum network would be the network that balances the errors generated with the number of hidden nodes. Thus, if the error term begins to increase after a particular point, then the network exhibits decreasing performance at its task of learning and forecasting the data series.

The NAR used in this article utilises one hidden node and two time delays. This was found to be the most reliable model after comparison to other combinations. Further, the LevenbergMarquardt algorithm, a more sophisticated version of the nonlinear least squares method, was used. The network was trained using $65 \%$ of the sample, validated on $25 \%$ and tested on $10 \%$ as per Looney (1996).

\section{The seasonally adjusted autoregressive integrated moving average model}

The autoregressive (AR) and moving average (MA) models were first introduced by Yule (1926) and Slutzky (1937), respectively. However, it was Wold (1938) who illustrated that a combination of these two models can be utilised to model a time series. Nonetheless, a time series may still exhibit non-stationary behaviour because of the presence of a trend or seasonal variations. To address this problem Box and Jenkins (1970) suggested the use of a SARIMA $(p, d, q)$ $\times(P, D, Q) S$ model, which can be formulated as follows (Box \& Jenkins 1970; Hong et al. 2011):

$\phi_{p}(B) \Phi_{P}\left(B^{S}\right) \nabla^{d} \nabla_{S}^{D} y_{t}=\theta_{q}(B) \Theta_{Q}\left(B^{S}\right) \varepsilon_{t}$,

[Eqn 11]

where $B$ denotes the backshift operator defined by $B^{a} y_{t}=y_{t-a} ; S$ denotes the seasonal length; $\nabla^{d}$ and $\nabla_{s}^{D}$ are the non-seasonal and seasonal difference operators of order $d$ and $D$, respectively, where $\nabla^{d}=(1-B)^{d}$ and $\nabla_{S}^{D}=\left(1-B^{S}\right)^{D} ; y_{t}$ denotes CPI inflation at time $t ; \phi_{p}(B)=\left(1-\phi_{1} B-\ldots-\phi_{p} B^{p}\right)$ and denotes the non-seasonal AR operator of order $p ; \Phi_{P}\left(B^{S}\right)=\left(1-\Phi_{1} B^{S}-\ldots-\Phi_{P} B^{P S}\right)$ and denotes the seasonal AR operator of order $P ; \theta_{q}(B)=\left(1-\theta_{1} B-\ldots-\theta_{q} B^{q}\right)$ and denotes the non-seasonal MA operator of order $q ; \Theta_{Q}\left(B^{s}\right)=\left(1-\Theta_{1} B^{S}-\ldots-\Theta_{Q} B^{Q S}\right)$ and denotes the seasonal MA operator of order $Q$; and $\varepsilon_{t}$ denotes the error term at time $t$, where $\varepsilon_{t} \sim N\left(0, \sigma^{2}\right)$.

This article will make use of the AIC to compare the goodness of fit of the different model specifications. Also, the adequacy of each model will be verified by the Ljung-Box test (Ljung \& Box 1978) and the autocorrelation function (ACF) of the standardised residuals. In order to make $y_{t}$ stationary and to eliminate all possible trends it must be differenced to the $d$-order. There are several tests popular amongst econometricians for testing the null hypothesis of a unit root to establish the order of integration. These tests include the Phillips-Perron (PP) test, the Dickey-Fuller test and the augmented Dickey-Fuller (ADF) test, where the ADF is preferred because it has more explanatory power than the rest of the tests in this category (Maddala \& Kim 2000). However, the PP test is the least popular test, as it suffers from very low power against trend stationary alternatives (DeJong et al. 1992). There are also several tests for testing stationarity with stationarity as the null hypothesis, which include the KPSS test (after Kwaitkowski et al. 1992), the Dickey-Fuller generalised least squares (DF-GLS) test, as well as tests by Leybourne and McCabe (1994) and Arellano and Pentula (1995). However, to ensure that the correct order of integration is established, the process proposed by Van Greunen et al. (2014) will be applied, which will make use of the ADF, KPSS and DF-GLS tests (see also Heymans et al. 2014). These tests will be estimated in the EViews $9 \AA$ econometric software program (IHS 2015b). Lastly, the Gretl (2010) econometric software program was chosen to estimate a d-parameter, with Geweke and Porter-Hudak's (1983) procedure, to assist in verifying the ideal order of integration.

\section{The additive Holt-Winters exponential smoothing approach}

Let $\left\{y_{t}, t \in \mathrm{Z}\right\}$ be the CPI inflation time series under evaluation, with a locally linear trend and additive seasonality of period $p \geq 2$. Consider the level $L_{t^{\prime}}$ the trend $T_{t}$ and the seasonal index $S_{t}$ at time $t$, where the $S$ values approximately sum up to 0 and repeat after period $p$ (Hanzák 2012). The calculation of level $L_{t}$ consists of a combination between the observed and the adjusted in period $t$, where the seasonal effect is removed from the series. Also, the calculation of trend $T_{t}$ entails the sequential difference of two consecutive levels, whereas the seasonal index $S_{t}$ consists of the combination between the observed and adjusted seasonal indices in period $t$ (Da Veiga et al. 2014).

Consider the forecast $\hat{y}_{t^{+} \tau}(\mathrm{t})$ of the future unknown observation $y_{t+\tau}, \tau>0$, which is constructed at time $t$ and can be formulated as follows (Hanzák 2012):

$\hat{y}_{t+\tau}(t)=\left(L_{t}+\tau\right) \times\left(T_{t}+S_{t \oplus \tau}\right)$,

[Eqn 12]

where $t \oplus \tau=\mathrm{t}+1-p+[(\tau-1) \bmod p]$. After the new observation $y_{t+1}$ is available, the level, trend and seasonal index can be updated by applying the following equations, respectively (Hanzák 2012):

$$
\begin{aligned}
& L_{t+1}=(1-\alpha) \times\left(L_{t}+T_{t}\right)+\alpha \times\left(y_{t+1}-S_{t+1-p}\right), \\
& T_{t+1}=(1-\gamma) \times\left(T_{t}+\gamma\right) \times\left(L_{t+1}-L_{t}\right), \text { and } \\
& S_{t+1}=(1-\delta) \times\left(S_{t+1-p}+\delta\right) \times\left(y_{t+1}-L_{t+1}\right),
\end{aligned}
$$

where $\alpha, \gamma, \delta \in(0,1]$ are the smoothing constants for the level, trend and seasonal indices, respectively. As soon as the seasonal component is additive, the error correction calculation to update the trend $T_{t}$ and the seasonal index $S_{t}$ can 
commence, by applying the following equations, respectively (Hanzák 2012):

$$
\begin{aligned}
& L_{t+1}=\left(L_{t}+T_{t}+\alpha\right) \times e_{t+1}, \\
& T_{t+1}=\left(T_{t}+\alpha\right) \times \gamma \times e_{t+1}, \\
& S_{t+1}=S_{t+1-p}+(1-\alpha) \times \delta \times e_{t+1},
\end{aligned}
$$

where $e_{t+1}=y_{t+1}-\hat{y}_{t+1}(t)$ is the one-step-ahead forecasting error at time $t+1$. Note that the components of the Holt-Winters exponential smoothing model are obtained by presetting the values of the constants $\alpha, \gamma, \delta$ in order to obtain the initial values for the model. It is only after this process that it becomes possible to establish the specific values for the parameters that minimise the sum of squared errors of the forecast one step ahead (Chatfield \& Yar 1988).

\section{Results}

In order to estimate the SARIMA model an autoregressivemoving average (ARMA) conditional least squares model was applied with the Gauss-Newton optimisation and Marquardt step method. The model optimisation criterion was based on the best F-statistic, Akaike information and SC, which suggested that the SARIMA $(1,0,1) \times(0,0,12)$ model specification is the superior alternative to consider. Additionally, the ACF exhibited both positive and negative spikes, suggesting the necessity of adding a seasonal AR (SAR) and MA (SMA) term, respectively. However, several alternative SAR terms were found insignificant, which is why it was excluded from the chosen model. Furthermore, no additional autocorrelation or partial correlation were present. The Breusch-Godfrey
Lagrange multiplier (LM) test also confirmed that no serial correlation was present, indicating that the model is suitable.

Evidence of over-differencing was also found, suggesting that first differencing, fractional differencing or seasonal differencing were insufficient, which is why the $I(0)$-series was used for further investigation. This approach is further motivated by the fact that expectation comparisons to those of the BER, IMF and SARB would be impossible if some form of differencing were to be applied, as the original data are transformed in the process. Inflation data are often deemed an $I(0)$-series (Brunner \& Hess 1993).

Tables 1 and 2 report on the yearly approach. The results emphasise the dominance of the additive Holt-Winters and SARIMA models over the NAR model and the expectations reported by the IMF. All three models outperformed the IMF for all the years concerned. The SARIMA approach outperformed all other forecasts for 2011, 2012 and 2015, while the Holt-Winters model's 1-year-ahead expectations outperformed the other forecasts during 2010 and 2013. Finally, the more complex counterpart under evaluation (NAR model) was only able to exhibit dominance during 2014, with the 1-year-ahead expectation comparisons. The results of the 2-year-ahead forecasts were similar in that all three models outperformed the IMF for all the years concerned again. The NAR model outperformed all other forecasts four out of six times, while the Holt-Winters model was superior twice.

From Table 2 it is clear that the NAR model exhibited slightly smaller AIC, SC, HQ and SE values for the 1-year-ahead

\begin{tabular}{|c|c|c|c|c|c|c|c|c|c|}
\hline \multirow{2}{*}{$\begin{array}{l}\text { Dates } \\
\text { forecasted }\end{array}$} & \multirow{2}{*}{$\begin{array}{c}\text { Actual consumer } \\
\text { inflation }\end{array}$} & \multicolumn{4}{|c|}{ 1-year-ahead expectations } & \multicolumn{4}{|c|}{ 2-year-ahead expectations } \\
\hline & & IMF & NAR & SARIMA & Holt-Winters & IMF & NAR & SARIMA & Holt-Winters \\
\hline 2010 & 3.82 & 5.64 & 3.99 & 4.08 & 3.95 & 5.50 & 4.04 & 4.04 & 3.76 \\
\hline 2011 & 5.44 & 5.70 & 5.32 & 5.40 & 5.28 & 4.71 & 5.36 & 5.27 & 5.23 \\
\hline 2012 & 5.54 & 4.80 & 5.49 & 5.55 & 5.52 & 5.50 & 5.52 & 5.58 & 5.56 \\
\hline 2013 & 5.73 & 5.25 & 5.78 & 5.81 & 5.76 & 5.00 & 5.62 & 5.81 & 5.77 \\
\hline 2014 & 5.99 & 5.40 & 6.12 & 6.16 & 6.13 & 4.90 & 6.07 & 6.12 & 6.08 \\
\hline 2015 & 4.73 & 5.80 & 4.67 & 4.73 & 4.61 & 5.10 & 4.63 & 4.66 & 4.61 \\
\hline
\end{tabular}
expectation comparisons over the entire period under

TABLE 1: Inflation expectation comparison with the International Monetary Fund - Yearly approach.

Note: The actual and forecasted values were converted from a monthly frequency to a yearly exponential weighted average.

\begin{tabular}{|c|c|c|c|c|c|c|c|c|}
\hline \multirow{2}{*}{$\begin{array}{l}\text { Accuracy } \\
\text { measures }\end{array}$} & \multicolumn{4}{|c|}{ 1-year-ahead expectations } & \multicolumn{4}{|c|}{ 2-year-ahead expectations } \\
\hline & IMF & NAR & SARIMA & Holt-Winters & IMF & NAR & SARIMA & Holt-Winters \\
\hline$\overline{\mathrm{AIC}}$ & 2.60 & -1.10 & -1.10 & -0.88 & 2.51 & -0.97 & -0.67 & -1.45 \\
\hline SC & 2.53 & -1.17 & -1.17 & -0.95 & 2.44 & -1.04 & -0.74 & -1.52 \\
\hline $\mathrm{HQ}$ & 2.32 & -1.38 & -1.38 & -1.16 & 2.23 & -1.24 & -0.94 & -1.72 \\
\hline SE & 0.94 & 0.07 & 0.07 & 0.08 & 1.03 & 0.08 & 0.09 & 0.05 \\
\hline RMSE & 0.64 & 0.10 & 0.10 & 0.11 & 0.61 & 0.11 & 0.12 & 0.08 \\
\hline MAD & 0.05 & 0.01 & 0.00 & 0.00 & 0.06 & 0.01 & 0.01 & 0.01 \\
\hline MAPE & 0.95 & 0.11 & 0.08 & 0.08 & 1.04 & 0.23 & 0.15 & 0.11 \\
\hline U & 0.00 & 0.00 & 0.00 & 0.00 & 0.00 & 0.00 & 0.00 & 0.00 \\
\hline
\end{tabular}

IMF, International Monetary Fund; NAR, non-linear autoregressive neural networks model; SARIMA, seasonally adjusted autoregressive integrated moving average model.

TABLE 2: Overall accuracy - Yearly approach.

Note: See Table 1-A1 in the Appendix 1 for a more detailed report.

IMF, International Monetary Fund; NAR, non-linear autoregressive neural networks model; SARIMA, seasonally adjusted autoregressive integrated moving average model; AIC, Akaike information criterion; SC, Schwarz criterion; HQ, Hannan-Quinn criterion; SE, standard error; RMSE, root mean squared error; MAD, mean absolute deviation; MAPE, mean absolute percentage error; U, Theil inequality coefficient. 
TABLE 3: Inflation expectation comparison with Bureau for Economic Research and South African Reserve Bank - Quarterly approach.

\begin{tabular}{|c|c|c|c|c|c|c|c|c|c|c|c|}
\hline \multirow{2}{*}{$\begin{array}{l}\text { Dates } \\
\text { forecasted }\end{array}$} & \multirow{2}{*}{$\begin{array}{l}\text { Actual consumer } \\
\text { inflation }\end{array}$} & \multicolumn{5}{|c|}{ 1-year-ahead expectations } & \multicolumn{5}{|c|}{ 2-year ahead expectations } \\
\hline & & BER & SARB & NAR & SARIMA & Holt-Winters & BER & SARB & NAR & SARIMA & Holt-Winters \\
\hline $2010 Q 1$ & 5.48 & 8.02 & 6.70 & 6.37 & 6.37 & 6.21 & 6.81 & 6.80 & 6.25 & 6.27 & 5.98 \\
\hline $2010 Q 2$ & 4.38 & 8.13 & 6.50 & 5.56 & 5.65 & 5.51 & 7.34 & 6.80 & 5.49 & 5.51 & 5.44 \\
\hline $2010 Q 3$ & 3.38 & 7.49 & 6.10 & 4.67 & 4.74 & 4.51 & 7.71 & 6.40 & 4.67 & 4.67 & 4.60 \\
\hline $2010 Q 4$ & 3.52 & 7.51 & 5.50 & 4.04 & 4.08 & 3.95 & 7.52 & 6.20 & 4.07 & 4.04 & 3.76 \\
\hline 2011Q1 & 3.90 & 6.68 & 5.70 & 3.63 & 3.87 & 3.65 & 7.79 & 6.00 & 3.71 & 3.70 & 3.63 \\
\hline 2011Q2 & 4.73 & 6.53 & 5.80 & 3.97 & 4.10 & 3.91 & 7.92 & 5.80 & 4.02 & 3.92 & 3.87 \\
\hline 2011Q3 & 5.50 & 6.12 & 5.90 & 4.58 & 4.71 & 4.55 & 7.46 & 5.90 & 4.58 & 4.53 & 4.60 \\
\hline 2011Q4 & 6.08 & 5.48 & 6.10 & 5.31 & 5.40 & 5.28 & 7.70 & 6.00 & 5.27 & 5.27 & 5.23 \\
\hline 2012Q1 & 6.08 & 5.75 & 6.10 & 5.80 & 5.91 & 5.77 & 6.76 & 6.00 & 5.86 & 5.82 & 5.78 \\
\hline 2012Q2 & 5.67 & 5.84 & 6.00 & 5.96 & 6.01 & 5.96 & 6.78 & 6.10 & 5.99 & 6.00 & 5.99 \\
\hline $2012 Q 3$ & 5.23 & 5.91 & 6.00 & 5.57 & 5.66 & 5.62 & 6.39 & 6.20 & 5.66 & 5.68 & 5.67 \\
\hline $2012 Q 4$ & 5.65 & 6.14 & 6.10 & 5.57 & 5.55 & 5.52 & 6.16 & 6.20 & 5.53 & 5.58 & 5.56 \\
\hline 2013Q1 & 5.82 & 6.11 & 6.00 & 5.57 & 5.58 & 5.48 & 6.00 & 6.10 & 5.61 & 5.57 & 5.52 \\
\hline
\end{tabular}

Notes: BER inflation expectations are the total amount of the surveys. The actual and forecasted values were converted from a monthly frequency to a yearly exponential weighted average BER, Bureau for Economic Research; SARB, South African Reserve Bank; NAR, non-linear autoregressive neural networks model; SARIMA, seasonally adjusted autoregressive integrated moving average model.

evaluation (2010-2015), whereas the SARIMA model was superior to the NAR and Holt-Winters models in terms of the RMSE, MAD, MAPE and U, making it the more ideal forecasting tool. In terms of the 2-year-ahead expectation comparisons over the entire period under evaluation (2010-2015), the Holt-Winters model exhibited overall dominance in terms of all the forecasting accuracy measures, as reported by Table 2, which also contradict the findings of Schulze and Prinz (2009).

When scrutinising the results of the quarterly approach in terms of the 1-year-ahead expectation comparisons (see Table 3), the outcome is fairly similar. The NAR model outperforms the BER expectations $79 \%$ of the time, whilst outperforming the SARB's expectations $71 \%$ of the time. The SARIMA model also outperforms the BER $79 \%$ of the time, but only manages to provide more accurate forecasts $64 \%$ of the time when compared to the SARB. The Holt-Winters model generated more accurate inflation expectations compared to the expectations reported by the BER and SARB $71 \%$ of the time.

Looking at the results of the quarterly approach in terms of the 2-year-ahead expectation comparisons (see Table 3), the forecasting models perform even better. Here, the NAR model outperforms the BER expectations $93 \%$ of the time, whilst outperforming the SARB's expectations $79 \%$ of the time. The SARIMA performs equally well, also managing to outperform the BER's expectations $93 \%$ of the time and outperforming the SARB's expectations $79 \%$ of the time. The Holt-Winters model manages a better forecast $93 \%$ of the time when compared to the BER and $71 \%$ of the time when compared to the SARB's expectations.

When scrutinising the findings reported in Table 3 by looking at the accuracy measures in Table 4, the Holt-Winters model exhibited the best forecasting accuracy over the 1-year and 2-year expectation comparisons, respectively. The SARIMA model was the only opposition, which reported better forecasting accuracy with some measures, although not sufficient to surpass the performance of the Holt-Winters
TABLE 4: Overall accuracy - Quarterly approach.

\begin{tabular}{lccccc}
\hline $\begin{array}{l}\text { Accuracy } \\
\text { measures }\end{array}$ & BER & SARB & NAR & SARIMA & Holt-Winters \\
\hline 1-year-ahead expectations & & & & \\
AIC & 2.29 & 2.77 & 2.27 & 2.24 & 2.20 \\
SC & 2.38 & 2.86 & 2.36 & 2.33 & 2.30 \\
HQ & 2.28 & 2.76 & 2.26 & 2.23 & 2.20 \\
SE & 0.22 & 0.84 & 0.23 & 0.24 & 0.23 \\
RMSE & 0.66 & 0.84 & 0.65 & 0.64 & 0.63 \\
MAD & 0.06 & 0.07 & 0.05 & 0.04 & 0.05 \\
MAPE & 1.78 & 1.98 & 1.43 & 1.25 & 1.30 \\
U & 0.00 & 0.00 & 0.00 & 0.00 & 0.00 \\
2-year-ahead expectations & & & & \\
AIC & 2.50 & 2.84 & 2.23 & 2.27 & 2.17 \\
SC & 2.59 & 2.93 & 2.32 & 2.36 & 2.26 \\
HQ & 2.49 & 2.83 & 2.22 & 2.26 & 2.16 \\
SE & 0.30 & 0.87 & 0.24 & 0.24 & 0.22 \\
RMSE & 0.73 & 0.87 & 0.64 & 0.65 & 0.62 \\
MAD & 0.08 & 0.11 & 0.05 & 0.05 & 0.04 \\
MAPE & 2.40 & 3.14 & 1.37 & 1.42 & 1.01 \\
U & 0.00 & 0.00 & 0.00 & 0.00 & 0.00 \\
\hline
\end{tabular}

Note: See Table 2-A1 in the Appendix 1 for a more detailed report.

$B E R$, Bureau for Economic Research; SARB, South African Reserve Bank; NAR, non-linear autoregressive neural networks model; SARIMA, seasonally adjusted autoregressive integrated moving average model; AIC, Akaike information criterion; SC, Schwarz criterion $\mathrm{HQ}$, Hannan-Quinn criterion; SE, standard error; RMSE, root mean squared error; $M A D$, mean absolute deviation; MAPE, mean absolute percentage error; $U$, Theil inequality coefficient.

model. The SARIMA model exhibited the lowest $U$ with the 2-year-ahead expectation comparisons and the lowest MAD, MAPE and U estimates with the 1-year-ahead expectations comparison.

Overall, the inflation forecast comparisons reported for both the quarterly and yearly approaches (see Tables 1 and 3) exhibited no consistency in under- or over-forecasting the actual inflation rates. Both the models under evaluation and the approaches applied by the BER, SARB and IMF exhibited variations of under- and over-forecasted estimates, with the exception of the SARB and BER. The SARB reported only over-forecasted estimates for the 1-year-ahead quarterly expectation comparison, whereas similar findings were reported for BER for the 2-year-ahead quarterly expectation comparison. The Holt-Winters model exhibited 
the smallest average deviation over both the quarterly and yearly approaches, thus emphasising the earlier findings.

It is, therefore, clear that less complex forecasting models, such as the Holt-Winters and SARIMA models, can generate reliable inflation expectations, therefore rendering the assumption that more complex models ensure greater accuracy invalid. This implies that, over the time horizon under evaluation, the HoltWinters and SARIMA models can be argued as suitable forecasting tools that can be used instead of or in conjunction with surveys to promote more effective alignment between public expectations and policymakers.

\section{Conclusion and recommendations}

The accuracy of the inflation expectations are critical; not only for policymakers but also for producers and consumers who build these expectations into asset and selling prices, as well as unions setting wage demands. Given the importance of accurate inflation expectations and the management thereof, this article explores the use of several forecasting models that might aid policymakers to forecast consumer inflation more accurately. By doing so, it is possible for the SARB to create a more stable financial environment over the short to medium run, through which monetary policy can fulfil a significant precondition for the attainment of economic growth and development over the long run.

The results showed that all three forecasting models provided more accurate forecasts than those of the IMF, the SARB and BER for all intervals concerned. The findings highlighted the fact that less complex models are able to assist policymakers more accurately than surveys. Because surveys cannot be conducted frequently, the SARIMA and Holt-Winters models can be used in conjunction with surveys to realise greater price stability. This can also be beneficial for other market participants, as these less complex models can enhance their short- to medium-run budgeting in the presence of volatile currencies and knock-on effects.

In addition to the NAR model, it would be interesting to evaluate the Kalman filter's performance in inflation forecasting, as it can adjust rapidly to changes in the market and allows real-time updates to fit (Punales 2011). The Kalman filter also supports estimations of both past, present and future states, even with the precise nature of the modelled system being unknown (Grewal 2001).

\section{Acknowledgements Competing interests}

The authors declare that they have no financial or personal relationships which may have inappropriately influenced them in writing this article.

\section{Authors' contributions}

C.V.H. and Y.S. were responsible for the empirical study, whereas A.H. was responsible for the literature study and the editing of the empirical study.

\section{References}

Ajam, T. \& Aron, J., 2009, 'Transforming fiscal governance', in J. Aron, B. Kahn \& G. Kingdon (eds.), South African economic policy under democracy, pp. 58-91, Oxford University Press, Oxford.

Akinboade, O.A. \& Niedermeier, E.W., 2002, 'Labour costs and inflation in South Africa: An econometric study', Studies in Economics and Econometrics 26(2), 1-18.

Alon, I., Qi, M. \& Sadowski, R.J., 2001, 'Forecasting aggregate retail sales: A comparison of artificial neural networks and traditional methods', Journal of Retailing and Consumer Services 8(3), 147-156. https://doi.org/10.1016/S0969-6989(00)00011-4

Arellano, C. \& Pentula, S.G., 1995, 'Testing for trend stationarity versus difference stationarity', Journal of Time Series Analysis 16(2), 147-164.

$\mathrm{Au}$, K.F., Choi, T.M. \& Yu, Y., 2008, 'Fashion retail forecasting by evolution neural networks', International Journal of Production Economics 114(2), 615-630. https:// doi.org/10.1016/j.ijpe.2007.06.013

Basheer, I. \& Hajmeer, M., 2000, 'Artificial neural networks: Fundamentals, computing, design, and application', Journal of Microbiological Methods 43(1), 3-31. https:// doi.org/10.1016/S0167-7012(00)00201-3

Bureau for Economic Research (BER), 2015, Data source, viewed 20 August 2015, from https://www.ber.ac.za/BER\%20Documents/Inflation-Expectations/?doctypeid=1065

Bishop, C.M., 1995, Neural networks for pattern recognition, Oxford University Press, New York.

Box, G.E.P. \& Jenkins, G.M., 1970, Time series analysis: Forecasting and control, Holden-Day, San Francisco, CA

Box, G.E.P. \& Jenkins, G.M., 1976, Time series analysis: Forecasting and control, rev. edn., Holden-Day, Oakland, CA.

Brunner, A.D. \& Hess, G.D., 1993, 'Are higher levels of inflation less predictable? A state-dependent conditional heteroscedasticity approach', Journal of Business \& Economic Statistics 11(2), 187-197.

Caire, P., Hatabian, G. \& Muller, C., 1992, Progress in forecasting by neural networks, viewed 07 September 2016, from http://ieeexplore.iee.org/stamp/stamp. jsp?tp=\&arnumber $=226932$

Chatfield, C. \& Yar, M., 1988, 'Holt-Winters forecasting: Some practical issues', Journa of the Royal Statistical Society. Series D (The Statistician) 37(2), 129-140. https:// doi.org/10.2307/2348687

Chen, C.F., Chang, Y.H. \& Chang, Y.W., 2009, 'Seasonal ARIMA forecasting of inbound air travel arrivals to Taiwan', Transportmetrica 5(2), 125-140. https://doi. org/10.1080/18128600802591210

Clarida, R., Gali, J. \& Gertler, M., 2000, 'Monetary policy rules and macroeconomic stability: Evidence and some theory', Quarterly Journal of Economics 115(1), 147-180. https://doi.org/10.1162/003355300554692

Connor, J.T., Martin, R.D. \& Atlas, L.E., 1994, 'Recurrent neural networks and robust time series prediction', IEEE Transactions on Neural Networks 5(2), 240-254. https://doi.org/10.1109/72.279188

Da Veiga, C.P., Da Veiga, C.R.P., Catapan, A., Tortato, U. \& Da Silva, W.V., 2014, 'Demand forecasting in food retail: A comparison between the Holt-Winters and ARIMA models', WSEAS Transactions on Business and Economics 11, 608-614.

De La Dehesa, G., 2008, Should the ECB adopt a flexible inflation targeting? viewed 11 March 2014, from www.europarl.europa.eu/document/activities/cont/200803/2 0080312ATT23990/20080312ATT23990EN.pdf

Demir, B. \& Yigit, T.M., 2008, 'Announcements and credibility under inflation targeting', Economics Letters 100(2), 249-253. https://doi.org/10.1016/j.econlet.2008. 02.002

Deng, J.L., 1982, 'Control problems of grey systems', Systems and Control Letters 1(1), 288-294.

De Wet, G.L. \& Associates, 1987, Inflasie in Suid-Afrika, Butterworths, Durban.

DeJong, D.N., Nankervis, J.C., Savin, N.E. \& Whiteman, C.H., 1992, 'Integration versus trend stationary in time series', Econometrica 60(2), 423-433. https://doi.org/ $10.2307 / 2951602$

Elman, J., 1991, 'Distributed representations, simple recurrent networks and grammatical structure', Machine Learning 7(2), 195-225. https://doi.org/10.1007/ BF00114844

Engle, R.F., 1982, 'Autoregressive conditional heteroscedasticity with estimates of the variance of United Kingdom inflation', Econometrica: Journal of the Econometric Society 50(4), 987-1007. https://doi.org/10.2307/1912773

Epstein, G. \& Yeldan, E., 2008, 'Inflation targeting, employment creation and economic development: Assessing the impacts and policy alternatives', International Review of Applied Economics 22(2), 131-144. https://doi.org/10.1080/02692170701880601

Faraway, J. \& Chatfield, C., 1998, 'Time series forecasting with neural networks: A comparative study using the airline data', Journal of the Royal Statistical Society. Series C (Applied Statistics) 47(2), 231-250. https://doi.org/10.1111/14679876.00109

Fernández-Rodríguez, F., González-Martel, C. \& Sosvilla-Rivero, S., 2000, 'On the profitability of technical trading rules based on artificial neural networks: Evidence from the Madrid stock market', Economics Letters 69(1), 89-94. https://doi. org/10.1016/S0165-1765(00)00270-6

Franses, P.H. \& Draisma, G., 1997, 'Recognizing changing seasonal patterns using artificial neural networks', Journal of Econometrics 81(1), 273-280. https://doi. org/10.1016/S0304-4076(97)00047-X

Friedman, M., 1968, 'The role of monetary policy', The American Economic Review 58(1), 1-17. 
Garth, A., Rollins, D., Zhu, J. \& Chen, V., 1996, 'Evaluation of model discrimination techniques in artificial neural networks with application to grain drying', Artificial Neural Networks in Engineering 6, 939-950.

Geweke, J. \& Porter-Hudak, A., 1983, 'The estimation application of long-memory time series models', Journal of Time Series Analysis 4(1), 221-238. https://doi. org/10.1111/j.1467-9892.1983.tb00371.x

Granger, C.W.J. \& Terasvirta, T., 1993, Modelling nonlinear economic relationships, Oxford University Press, Oxford.

Gretl, 2010, viewed 21 August 2015, from http://gretl.sourceforge.net/

Grewal, M.S., 2001, Kalman filtering, Springer, Berlin.

Gujarati, D.N., 2003, Basic econometrics, 4th edn., McGraw Hill, Boston, MA.

Hanzák, T., 2012, 'Holt-Winters method with general seasonality', Kybernetika 48(1), 1-15.

Haykin, S.S., 2009, Neural networks and learning machines, vol. 3, Pearson Education, Upper Saddle River, NJ.

Heymans, A., Van Heerden, C., Van Greunen, J. \& Van Vuuren, G., 2014, 'Diligence in determining the appropriate form of stationarity', Acta Commercii 14(1), 1-14. https://doi.org/10.4102/ac.v14i1.210

Hlaváček, M., Koňák, M. \& Čada, J., 2005, The application of structured feedforward neural networks to the modelling of daily series of currency in circulation, Working paper series 11, viewed 21 August 2015, from http://core.ac.uk/download/ paper series 11,
pdf/7362409.pdf

Hong, W.C., Dong, Y., Zheng, F. \& Lai, C.Y., 2011, 'Forecasting urban traffic flow by SVR with continuous ACO', Applied Mathematical Modelling 35(3), 1282-1291. https://doi.org/10.1016/j.apm.2010.09.005

IHS (IHS Global Inc), 2015a, Eviews user guide 2, viewed 07 September 2016, from http://www.eviews.com/home.html

IHS (IHS Global Inc), 2015b, Eviews user guide 1, viewed 07 September 2016, from http://www.eviews.com/home.html

International Monetary Fund (IMF), 2008-2014, Various data sources, viewed 20 August 2015, from http://www.imf.org/external/ns/cs.aspx?id=28

Kahn, B., 2008, Challenges of inflation targeting for emerging-market economies: The South African case, viewed 07 September 2016, from http://www2.resbank. South African case, viewed 07 September 2016, from $\mathrm{http}: / / \mathrm{www}$.resbank.
co.za/internet/Publication.nsf/LADV/1375D655561CAD9E4225760100384B88/\$ Fo.za/internet/Publicat

Karodia, A.M. \& Soni, P., 2016, 'President Jacob Zuma and South Africa's financial crisis: A Machivellian debacle', International Business Research 9(7), 24-54. https://doi.org/10.5539/ibr.v9n7p24

Kaseeram, l., Nichola, T. \& Mainardi, S., 2004, 'South African inflationary dynamics and the pass-through effects from depreciation to unit labour costs', The South African Journal of Economics 72(1), 83-105. https://doi.org/10.1111/j.1813-6982.2004. tb00105.x

Kershoff, G.J. \& Smit, B.W., 2002, 'Conducting inflation expectation surveys in South Africa', South African Journal of Economics 70(3), 445-460. https://doi.org/ 10.1111/j.1813-6982.2002.tb01299.x

Kinda, T., 2013, 'Oil windfall, public spending and price stability: Modelling inflation in Chad', Applied Economics 45(21), 3122-3135. https://doi.org/10.1080/00036846 .2012.690851

Kwaitkowski, D., Phillips, P.C.B., Schmidt, P. \& Shin, Y., 1992, 'Testing the null hypothesis of stationarity against the alternative of a unit root', Journal of Econometrics 54(1), 159-178. https://doi.org/10.1016/0304-4076(92)90104-Y

Kydland, F.E. \& Prescott, E.C., 1977, 'Rules rather than discretion - The inconsistency of optimal plans', Journal of Political Economy 85(3), 473-491. https://doi. org/10.1086/260580

Leybourne, S.J. \& McCabe, B.P.M., 1994, 'A consistent test for a unit root', Journal of Business and Economic Statistics 12(2), 157-166.

Lim, C.H. \& Papi, L., 1997, An econometric analysis of the determinants of inflation in Turkey, Working paper series no. 97/170, International Monetary Fund, viewed 09 September 2016, from https://www.imf.org/external/pubs/ft/wp/ wp97170.pdf

Ljung, G.M. \& Box, G.E., 1978, 'On a measure of lack of fit in time series models', Biometrika 65(2), 297-303. https://doi.org/10.1093/biomet/65.2.297

Looney, C., 1996, 'Advances in feed forward neural networks demystifying knowledge acquiring black boxes', IEEE Transactions on Knowledge and Data Engineering 8(2), 211-226. https://doi.org/10.1109/69.494162

Maddala, G.S. \& Kim, I.M., 2000, Unit roots, co-integration, and structural change, Cambridge University Press, Cambridge.

Maier, H.R. \& Dandy, G.C., 1996, 'Neural network models for forecasting univariate time series', Neural Networks World 6(5), 747-772.

McAdam, P. \& McNelis, P., 2005, 'Forecasting inflation with thick models and neural networks', Economic Modelling 22(5), 848-867. https://doi.org/10.1016/j. econmod.2005.06.002

McCulloch, W.S. \& Pitts, W., 1943, 'A logical calculus of the ideas immanent in nervous activity', The Bulletin of Mathematical Biophysics 5(4), 115-133. https://doi. org/10.1007/BF02478259

Mehrotra, A. \& Sánchez-Fung, J.R., 2008, 'Forecasting inflation in China', China Economic Journal 1(3), 317-322. https://doi.org/10.1080/17538960802567818

Mishkin, F.S., 2004, Can inflation targeting work in emerging market countries? Working paper series no. 10646, NBER, viewed 09 September 2016, from http:// www.nber.org/papers/w10646
Naraidoo, R. \& Gupta, R., 2010, 'Modeling monetary policy in South Africa: Focus on inflation targeting era using a simple learning rule', International Business \& Economics Research Journal 9(12), 89-98. https://doi.org/10.19030/iber.v9i12.349

Ortiz, A. \& Sturzenegger, F., 2007, 'Estimating SARB's policy reaction rule', The South African Journal of Economics 75(4), 659-680. https://doi.org/10.1111/j.18136982.2007.00146.x

Pankratz, A., 1983, Forecasting with univariate Box-Jenkins models: Concepts and cases, Wiley, New York.

Powers, C., 2005, 'Inflation targeting: A comparative assessment of South Africa's early experience', Master's dissertation, RAU, Johannesburg.

Punales, A.G.S., 2011, Time-varying coefficient model and the Kalman filter: Applications to hedge funds, viewed 07 September 2016, from http://digital. library.ryerson.ca/islandora/object/RULA\%3A2193

Rafiq, M.Y., Bugmann, G. \& Easterbrook, D.J., 2001, 'Neural network design for engineering applications', Computers \& Structures 79(17), 1541-1552. https://doi. engineering applications', Computers $\&$
org/10.1016/S0045-7949(01)00039-6

Rangasamy, L., 2009, 'Inflation persistence and core inflation: The case of South Africa', South African Journal of Economics 77(3), 430-444. https://doi. org/10.1111/j.1813-6982.2009.01222.x

Ricci, L.A., 2005, 'Bringing inflation under control', in M. Nowak \& L.A. Ricci (eds.), Post apartheid South Africa: The first ten years, pp. 189-210, International Monetary Fund, Washington, DC

Rosenblatt, F., 1958, 'The perceptron: A probabilistic model for information storage and organization in the brain', Psychological Review 65(6), 386-396. https://doi. org/10.1037/h0042519

Rossouw, J., 2005, 'Monetêre beleid in Suid-Afrika sedert 1965: Die vordering vanaf direkte beheer tot inflasieteikens', Tydskrif vir Geesteswetenskappe 45(2), 292-300.

Schulze, P.M. \& Prinz, A., 2009, 'Forecasting container transshipment in Germany', Applied Economics 41(22), 2809-2815. https://doi.org/10.1080/0003684080 2260932

Serju, P., 2002, Monetary conditions \& core inflation: An application of neural networks, viewed 07 September 2016, from http://boj.org.jm/uploads/pdf/ papers_pamphlets/papers_pamphlets_monetary_conditions_and_core_ papers_pamphlets/papers_pamphlets_monetar

Setterfield, M., 2006, 'Is inflation targeting compatible with post Keynesian economics?', Journal of Post Keynesian Economics 28(4), 653-671. https://doi. economics?', Journal of Post Keynesiar
org 2753 PKE160-3477280407

Sharda, R. \& Patil, R., 1990, 'Neural networks as forecasting exports: An empirical test', Proceedings of the International Joint Conference on Neural Networks 2, 491-494.

Slutzky, E., 1937, 'The summation of random causes as the source of cyclic processes', Econometrica: Journal of the Econometric Society 5(2), 105-146. https://doi. org/10.2307/1907241

South African Reserve Bank (SARB), 2016, Data source, viewed 07 September 2016, from https://www.resbank.co.za/Research/Statistics/Pages/OnlineDownloadFacility.aspx

Statistics South Africa (STATSSA), 2015, Data source, viewed 07 September 2016, from http://www.statssa.gov.za/publications/P0141/CPIHistory.pdf?

Stiglitz, J.E., 2008, The failure of inflation targeting, viewed 07 September 2016, from https://www.economics.utoronto.ca/gindart/Stiglitz\%20-\%20The\%20Failure\%20 https://www.economics. utoron
of\%20Inflation 20Targeting.pdf

Strydom, P.D.F. \& Steenkamp, L., 1976, 'Inflation in South Africa II: Aggregate demand and price expectations', South African Journal of Economics 44(4), 417-434. https://doi.org/10.1111/j.1813-6982.1976.tb00497.x

Svensson, L.E.O., 1999, 'Inflation targeting as a monetary policy rule', Journal of Monetary Economics 43(3), 607-654. https://doi.org/10.1016/S0304-3932(99) 00007-0

Swanson, N.R. \& White, H., 1997, 'A model selection approach to real-time macroeconomic forecasting using linear models and artificial neural networks' Review of Economics and Statistics 79(4), 540-550. https://doi.org/10.1162/ 003465397557123

The MathWorks, Inc., 2010, viewed 20 February 2016, from http://www.mathworks. com/help/matlab/getting-started-with-matlab.html

Tkacz, G. \& Hu, S., 1999, Forecasting GDP growth using artificial neural networks, Working paper series no. 99-3, Bank of Canada, viewed 09 September 2016, from http://citeseerx.ist.psu.edu/viewdoc/download?doi=10.1.1.163.7999\&rep=rep1 \&type=pdf

Tong, H. \& Lim, K.S., 1980, 'Threshold autoregression, limit cycles and cyclical data' Journal of the Royal Statistical Society 42(3), 245-292.

Van Der Merwe, E.J., 2004, Inflation targeting in South Africa, Working paper series no. 19, South African Reserve Bank, viewed 09 September 2016, from http:// citeseerx.ist.psu.edu/viewdoc/download?doi=10.1.1.525.3159\&rep=rep1\&typ e=pdf

Van Greunen, J., Heymans, A., Van Heerden, C. \& Van Vuuren, G., 2014, 'The prominence of stationarity in time series forecasting', Studies in Economics and Econometrics 38(1), 1-16.

Van Heerden, C. \& Heymans, A., 2011, 'The relationship between the forward and realised spot exchange rate in South Africa', Journal of Economic and Financial Sciences 5(1), 175-192.

Vellido, A., Lisboa, P.J. \& Vaughan, J., 1999, 'Neural networks in business: A survey of applications (1992-1998)', Expert Systems with Applications 17(1), 51-70. https:// doi.org/10.1016/S0957-4174(99)00016-0 
Winters, P.R., 1960, 'Forecasting sales by exponentially weighted moving averages', Management Science 6(3), 324-342. https://doi.org/10.1287/mnsc.6.3.324

Woglom, G., 2005, 'Forecasting South African inflation', South African Journal of Economics 73(2), 302-320. https://doi.org/10.1111/j.1813-6982.2005.00019.x

Wold, H., 1938, A study in the analysis of stationary time series, Almqvist \& Wiksells, Uppsala.
Yule, G.U., 1926, 'Why do we sometimes get nonsense-correlations between timeseries? - A study in sampling and the nature of time-series', Journal of the Royal Statistical Society 89(1), 1-63. https://doi.org/10.2307/2341482

Zhang, G., Patuwo, B.E. \& Hu, M.Y., 1998, 'Forecasting with artificial neural networks: The state of the art', International Journal of Forecasting 14(1), 35-62. https://doi. org/10.1016/S0169-2070(97)00044-7

Appendix starts on the next page $\rightarrow$ 


\section{Appendix 1}

TABLE 1-A1: Inflation accuracy comparison with the International Monetary Fund - Yearly approach.

\begin{tabular}{|c|c|c|c|c|c|c|c|c|}
\hline Dates forecasted & AIC & SC & $\mathrm{HQ}$ & SE & RMSE & MAD & MAPE & $u$ \\
\hline \multicolumn{9}{|c|}{ SARIMA 1-year-ahead expectations } \\
\hline 2010 & 0.66 & 0.74 & 0.63 & 0.09 & 0.28 & 0.03 & 0.63 & 0.00 \\
\hline 2011 & -0.10 & -0.02 & -0.13 & 0.07 & 0.19 & 0.00 & 0.09 & 0.00 \\
\hline 2012 & 0.22 & 0.30 & 0.19 & 0.17 & 0.23 & 0.02 & 0.33 & 0.00 \\
\hline 2013 & 0.58 & 0.66 & 0.55 & 0.33 & 0.27 & 0.01 & 0.20 & 0.00 \\
\hline 2014 & 0.49 & 0.57 & 0.46 & 0.24 & 0.26 & 0.01 & 0.21 & 0.00 \\
\hline 2015 & 0.51 & 0.59 & 0.48 & 0.19 & 0.26 & 0.03 & 0.56 & 0.00 \\
\hline \multicolumn{9}{|c|}{ SARIMA 2-year-ahead expectations } \\
\hline 2010 & -0.05 & 0.03 & -0.08 & 0.06 & 0.20 & 0.00 & 0.02 & 0.00 \\
\hline 2011 & -0.45 & -0.36 & -0.48 & 0.06 & 0.16 & 0.01 & 0.27 & 0.00 \\
\hline 2012 & 0.42 & 0.50 & 0.39 & 0.18 & 0.25 & 0.02 & 0.29 & 0.00 \\
\hline 2013 & 0.84 & 0.92 & 0.81 & 0.30 & 0.31 & 0.01 & 0.12 & 0.00 \\
\hline 2014 & 0.59 & 0.67 & 0.56 & 0.25 & 0.27 & 0.01 & 0.12 & 0.00 \\
\hline 2015 & 0.89 & 0.97 & 0.86 & 0.28 & 0.32 & 0.01 & 0.28 & 0.00 \\
\hline 2010 & 2.13 & 2.21 & 2.10 & 0.21 & 0.59 & 0.01 & 0.29 & 0.00 \\
\hline 2011 & 1.13 & 1.21 & 1.10 & 0.15 & 0.36 & 0.01 & 0.26 & 0.00 \\
\hline 2012 & 0.82 & 0.90 & 0.79 & 0.22 & 0.31 & 0.01 & 0.16 & 0.00 \\
\hline 2013 & 0.52 & 0.61 & 0.49 & 0.28 & 0.27 & 0.01 & 0.14 & 0.00 \\
\hline 2014 & -0.22 & -0.14 & -0.25 & 0.16 & 0.18 & 0.01 & 0.14 & 0.00 \\
\hline 2015 & -0.79 & -0.71 & -0.82 & 0.14 & 0.14 & 0.01 & 0.27 & 0.00 \\
\hline \multicolumn{9}{|c|}{ Holt-Winters 2-year-ahead expectations } \\
\hline 2010 & -0.23 & -0.15 & -0.26 & 0.05 & 0.18 & 0.00 & 0.03 & 0.00 \\
\hline 2011 & -0.36 & -0.27 & -0.39 & 0.06 & 0.17 & 0.02 & 0.42 & 0.00 \\
\hline 2012 & 0.89 & 0.97 & 0.86 & 0.23 & 0.32 & 0.01 & 0.22 & 0.00 \\
\hline 2013 & 0.69 & 0.77 & 0.66 & 0.27 & 0.29 & 0.00 & 0.06 & 0.00 \\
\hline 2014 & 0.68 & 0.76 & 0.65 & 0.18 & 0.29 & 0.00 & 0.04 & 0.00 \\
\hline 2015 & -0.16 & -0.08 & -0.19 & 0.15 & 0.19 & 0.01 & 0.13 & 0.00 \\
\hline \multicolumn{9}{|c|}{ NAR 1-year-ahead expectations } \\
\hline 2012 & 0.36 & 0.44 & 0.33 & 0.18 & 0.24 & 0.02 & 0.31 & 0.00 \\
\hline 2013 & 0.74 & 0.82 & 0.71 & 0.24 & 0.30 & 0.01 & 0.12 & 0.00 \\
\hline 2014 & 0.55 & 0.63 & 0.52 & 0.25 & 0.27 & 0.01 & 0.11 & 0.00 \\
\hline 2015 & 0.73 & 0.81 & 0.70 & 0.25 & 0.30 & 0.02 & 0.36 & 0.00 \\
\hline \multicolumn{9}{|c|}{ NAR 2-year-ahead expectations } \\
\hline 2010 & -0.52 & -0.44 & -0.55 & 0.05 & 0.16 & 0.01 & 0.25 & 0.00 \\
\hline 2011 & -0.44 & -0.36 & -0.47 & 0.06 & 0.16 & 0.02 & 0.37 & 0.00 \\
\hline 2012 & 0.35 & 0.43 & 0.32 & 0.17 & 0.24 & 0.02 & 0.31 & 0.00 \\
\hline 2013 & 0.74 & 0.83 & 0.71 & 0.25 & 0.30 & 0.01 & 0.12 & 0.00 \\
\hline 2014 & 0.54 & 0.62 & 0.51 & 0.24 & 0.27 & 0.01 & 0.11 & 0.00 \\
\hline 2015 & 0.66 & 0.74 & 0.63 & 0.24 & 0.28 & 0.02 & 0.36 & 0.00 \\
\hline
\end{tabular}

AIC, Akaike information criterion; SC, Schwarz criterion; HQ, Hannan-Quinn criterion; SE, standard error; RMSE, root mean squared error; MAD, mean absolute deviation; MAPE, mean absolute percentage error; $\mathrm{U}$, Theil inequality coefficient; SARIMA, seasonally adjusted autoregressive integrated moving average model; NAR, non-linear autoregressive neural networks model. 
TABLE 2-A1: Inflation accuracy comparison with Bureau for Economic Research and South African Reserve Bank - Quarterly approach.

\begin{tabular}{|c|c|c|c|c|c|c|c|c|}
\hline Dates forecasted & AIC & SC & $\mathrm{HQ}$ & SE & RMSE & MAD & MAPE & U \\
\hline \multicolumn{9}{|c|}{ SARIMA 1-year-ahead expectations } \\
\hline 2010Q1 & 1.50 & 1.58 & 1.47 & 0.18 & 0.43 & 0.07 & 1.08 & 0.00 \\
\hline $2010 Q 2$ & 1.31 & 1.39 & 1.28 & 0.17 & 0.39 & 0.02 & 0.27 & 0.00 \\
\hline $2010 Q 3$ & 0.58 & 0.66 & 0.55 & 0.08 & 0.27 & 0.02 & 0.36 & 0.00 \\
\hline $2010 Q 4$ & 0.66 & 0.74 & 0.63 & 0.09 & 0.28 & 0.03 & 0.63 & 0.00 \\
\hline 2011Q1 & 0.64 & 0.72 & 0.61 & 0.20 & 0.28 & 0.01 & 0.36 & 0.00 \\
\hline 2011Q2 & 0.34 & 0.42 & 0.31 & 0.17 & 0.24 & 0.00 & 0.05 & 0.00 \\
\hline 2011Q3 & 0.09 & 0.17 & 0.06 & 0.09 & 0.21 & 0.02 & 0.60 & 0.00 \\
\hline 2011Q4 & -0.10 & -0.02 & -0.13 & 0.07 & 0.19 & 0.00 & 0.09 & 0.00 \\
\hline 2012Q1 & -0.49 & -0.40 & -0.52 & 0.07 & 0.16 & 0.02 & 0.30 & 0.00 \\
\hline 2012Q2 & -0.30 & -0.22 & -0.33 & 0.15 & 0.18 & 0.02 & 0.30 & 0.00 \\
\hline $2012 Q 3$ & 0.36 & 0.44 & 0.33 & 0.17 & 0.25 & 0.01 & 0.19 & 0.00 \\
\hline $2012 Q 4$ & 0.22 & 0.30 & 0.19 & 0.17 & 0.23 & 0.02 & 0.33 & 0.00 \\
\hline $2013 Q 1$ & 0.41 & 0.49 & 0.38 & 0.25 & 0.25 & 0.04 & 0.84 & 0.00 \\
\hline \multicolumn{9}{|c|}{ SARIMA 2-year-ahead expectations } \\
\hline 2010Q1 & 1.03 & 1.11 & 1.00 & 0.12 & 0.34 & 0.01 & 0.14 & 0.00 \\
\hline $2010 Q 2$ & 0.56 & 0.64 & 0.53 & 0.13 & 0.27 & 0.00 & 0.05 & 0.00 \\
\hline $2010 Q 3$ & 0.59 & 0.67 & 0.56 & 0.09 & 0.27 & 0.01 & 0.08 & 0.00 \\
\hline $2010 Q 4$ & -0.05 & 0.03 & -0.08 & 0.06 & 0.20 & 0.00 & 0.02 & 0.00 \\
\hline 2011Q1 & 0.07 & 0.15 & 0.04 & 0.12 & 0.21 & 0.02 & 0.59 & 0.00 \\
\hline 2011Q2 & 0.53 & 0.61 & 0.50 & 0.22 & 0.27 & 0.02 & 0.48 & 0.00 \\
\hline 2011Q3 & -0.41 & -0.33 & -0.44 & 0.07 & 0.17 & 0.00 & 0.07 & 0.00 \\
\hline 2011Q4 & -0.45 & -0.36 & -0.48 & 0.06 & 0.16 & 0.01 & 0.27 & 0.00 \\
\hline 2012Q1 & -0.47 & -0.39 & -0.50 & 0.07 & 0.16 & 0.01 & 0.13 & 0.00 \\
\hline 2012Q2 & -0.20 & -0.12 & -0.23 & 0.16 & 0.19 & 0.02 & 0.30 & 0.00 \\
\hline $2012 Q 3$ & 0.53 & 0.61 & 0.50 & 0.19 & 0.27 & 0.02 & 0.36 & 0.00 \\
\hline 2012Q4 & 0.42 & 0.50 & 0.39 & 0.18 & 0.25 & 0.02 & 0.29 & 0.00 \\
\hline $2013 Q 1$ & 0.60 & 0.68 & 0.57 & 0.25 & 0.28 & 0.05 & 1.07 & 0.00 \\
\hline 2010Q1 & 2.03 & 2.11 & 2.00 & 0.23 & 0.56 & 0.00 & 0.02 & 0.00 \\
\hline 2010Q2 & 1.26 & 1.34 & 1.23 & 0.20 & 0.39 & 0.01 & 0.15 & 0.00 \\
\hline $2010 Q 3$ & 1.21 & 1.29 & 1.18 & 0.11 & 0.37 & 0.00 & 0.01 & 0.00 \\
\hline $2010 Q 4$ & 2.13 & 2.21 & 2.10 & 0.21 & 0.59 & 0.01 & 0.29 & 0.00 \\
\hline 2011Q1 & 0.87 & 0.95 & 0.84 & 0.22 & 0.32 & 0.03 & 0.72 & 0.00 \\
\hline 2011Q2 & 0.02 & 0.10 & -0.01 & 0.16 & 0.21 & 0.01 & 0.42 & 0.00 \\
\hline 2011Q3 & 0.96 & 1.04 & 0.93 & 0.15 & 0.33 & 0.02 & 0.48 & 0.00 \\
\hline $2011 Q 4$ & 1.13 & 1.21 & 1.10 & 0.15 & 0.36 & 0.01 & 0.26 & 0.00 \\
\hline 2012Q1 & 1.52 & 1.60 & 1.49 & 0.23 & 0.44 & 0.01 & 0.17 & 0.00 \\
\hline 2012Q2 & 0.54 & 0.62 & 0.51 & 0.29 & 0.27 & 0.02 & 0.38 & 0.00 \\
\hline $2012 Q 3$ & 0.69 & 0.77 & 0.66 & 0.20 & 0.29 & 0.03 & 0.54 & 0.00 \\
\hline $2012 Q 4$ & 0.82 & 0.90 & 0.79 & 0.22 & 0.31 & 0.01 & 0.16 & 0.00 \\
\hline $2013 Q 1$ & 0.58 & 0.66 & 0.55 & 0.25 & 0.27 & 0.05 & 1.09 & 0.00 \\
\hline $2013 Q 2$ & 0.69 & 0.77 & 0.66 & 0.25 & 0.29 & 0.01 & 0.17 & 0.00 \\
\hline \multicolumn{9}{|c|}{ Holt-Winters 2-year-ahead expectations } \\
\hline 2010Q1 & 1.34 & 1.42 & 1.31 & 0.13 & 0.40 & 0.01 & 0.14 & 0.00 \\
\hline $2010 Q 2$ & 1.11 & 1.19 & 1.08 & 0.15 & 0.36 & 0.01 & 0.19 & 0.00 \\
\hline $2010 Q 3$ & 1.21 & 1.29 & 1.18 & 0.12 & 0.37 & 0.03 & 0.51 & 0.00 \\
\hline $2010 Q 4$ & -0.23 & -0.15 & -0.26 & 0.05 & 0.18 & 0.00 & 0.03 & 0.00 \\
\hline 2011Q1 & -0.03 & 0.05 & -0.06 & 0.09 & 0.20 & 0.02 & 0.47 & 0.00 \\
\hline 2011Q2 & 0.75 & 0.83 & 0.72 & 0.23 & 0.30 & 0.01 & 0.30 & 0.00 \\
\hline 2011Q3 & -0.33 & -0.25 & -0.36 & 0.06 & 0.17 & 0.01 & 0.26 & 0.00 \\
\hline $2011 Q 4$ & -0.36 & -0.27 & -0.39 & 0.06 & 0.17 & 0.02 & 0.42 & 0.00 \\
\hline 2012Q1 & 0.68 & 0.76 & 0.65 & 0.14 & 0.29 & 0.01 & 0.24 & 0.00 \\
\hline $2012 Q 2$ & 0.06 & 0.14 & 0.03 & 0.18 & 0.21 & 0.02 & 0.31 & 0.00 \\
\hline 2012Q3 & 0.84 & 0.92 & 0.81 & 0.22 & 0.31 & 0.03 & 0.49 & 0.00 \\
\hline $2012 Q 4$ & 0.89 & 0.97 & 0.86 & 0.23 & 0.32 & 0.01 & 0.22 & 0.00 \\
\hline 2013Q1 & 0.61 & 0.70 & 0.59 & 0.25 & 0.28 & 0.05 & 1.11 & 0.00 \\
\hline
\end{tabular}


TABLE 2-A1: Inflation accuracy comparison with Bureau for Economic Research and South African Reserve Bank - Quarterly approach (cont.).

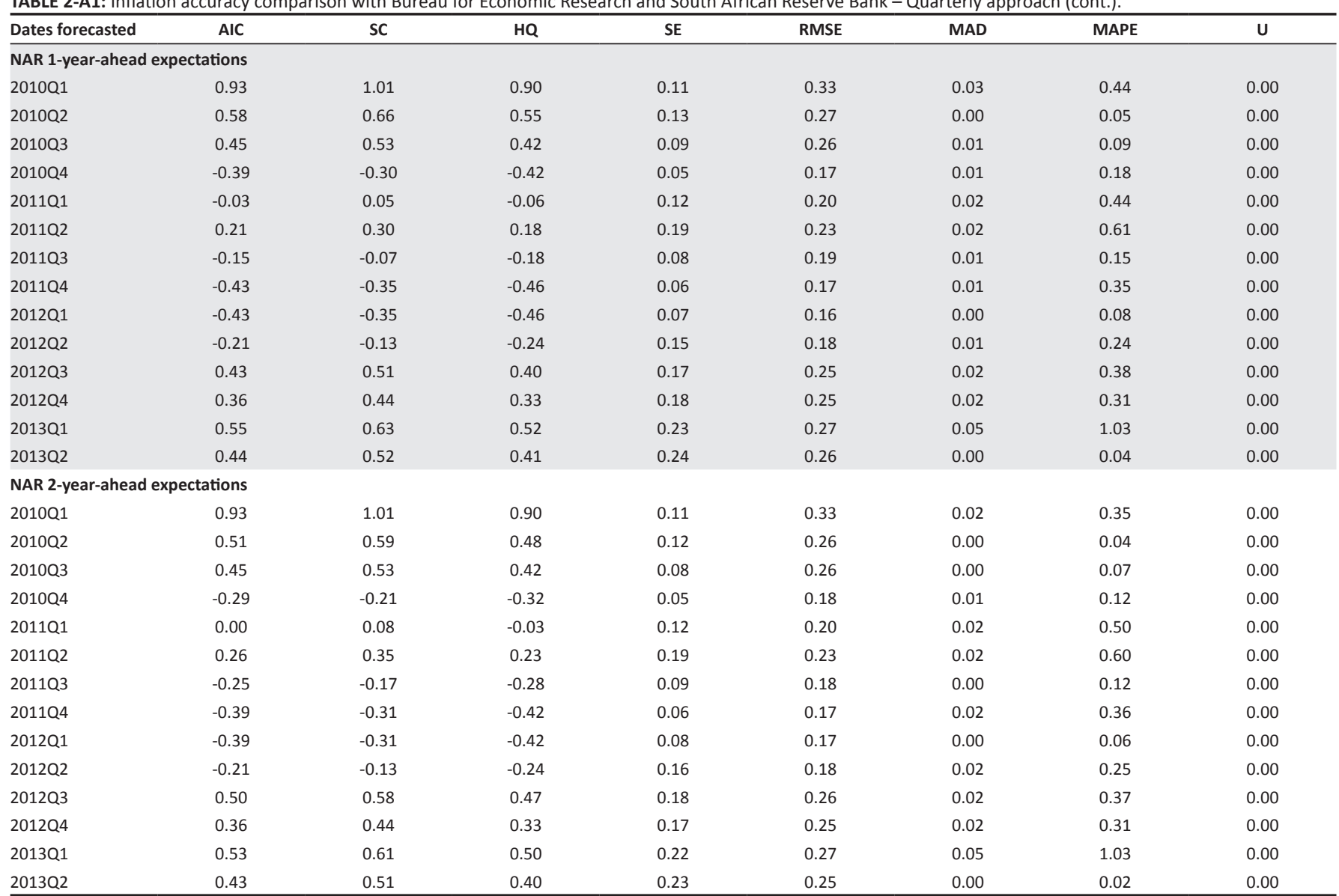

AIC, Akaike information criterion; SC, Schwarz criterion; HQ, Hannan-Quinn criterion; SE, standard error; RMSE, root mean squared error; MAD, mean absolute deviation; MAPE, mean absolute percentage error; $U$, Theil inequality coefficient; SARIMA, seasonally adjusted autoregressive integrated moving average model; NAR, non-linear autoregressive neural networks model. 